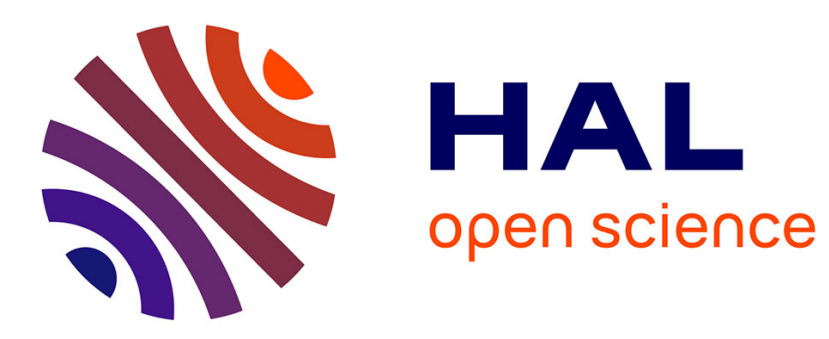

\title{
Enhancing Printable Concrete Thixotropy by High Shear Mixing
}

Aileen Vandenberg, Hela Bessaies Bey, Kay Wille, Nicolas Roussel

\section{To cite this version:}

Aileen Vandenberg, Hela Bessaies Bey, Kay Wille, Nicolas Roussel. Enhancing Printable Concrete Thixotropy by High Shear Mixing. Digital Concrete \&apos;18: First Rilem International Conference on Concrete and Digital Fabrication, Sep 2018, ZURICH, Switzerland. pp. 94-101, 10.1007/978-3319-99519-9_9. hal-01913688v2

\section{HAL Id: hal-01913688 \\ https://hal.science/hal-01913688v2}

Submitted on 21 Feb 2022

HAL is a multi-disciplinary open access archive for the deposit and dissemination of scientific research documents, whether they are published or not. The documents may come from teaching and research institutions in France or abroad, or from public or private research centers.
L'archive ouverte pluridisciplinaire HAL, est destinée au dépôt et à la diffusion de documents scientifiques de niveau recherche, publiés ou non, émanant des établissements d'enseignement et de recherche français ou étrangers, des laboratoires publics ou privés. 


\title{
Enhancing Printable Concrete Thixotropy by High Shear Mixing
}

\author{
Aileen Vandenberg ${ }^{1}$, Hela Bessaies-Bey ${ }^{2}$, Kay Wille ${ }^{1}$, and Nicolas Roussel ${ }^{2}$ \\ ${ }^{1}$ University of Connecticut, Storrs CT 06269, USA \\ ${ }^{2}$ IFSTTAR, Marne-la-Vallée 77420, France \\ aileen.c.vandenberg@gmail.com
}

\begin{abstract}
Our results show that the storage elastic modulus as a function of time increases at a higher rate for the cement paste mixed at higher versus lower mixing intensity. Hence, higher mixing appears to be enhancing thixotropy. Using calorimetry analysis we find that higher mixing decreases the setting time and enhances the peak of the heat flow. By analyzing the nanoparticles present in the suspending fluid of the cement paste, we show, in accordance with literature, that an appropriate combination of mixing energy and super-plasticizer dosage promotes hydration by scratching hydrates from the surface of cement particles, stabilizing them in the suspending fluid and hence generating additional nucleation surfaces. These results open the door for the design of printing heads including high-shear micro mixers allowing for a faster liquid-to-solid transition of the printable material.
\end{abstract}

Keywords: thixotropy, nanoparticles, mixing, cement, calorimetry, DLS.

\section{$1 \quad$ Introduction}

With the advent of concrete digital fabrication paving new ways of construction [1], controlling cement paste thixotropy is crucial to ensuring the desired final state of the material is achieved. Each digitally fabricated concrete layer has to evolve from a fluid suspension during mixing and pumping to a cohesive material after deposition that maintains a strong interface with, and mechanical resistance to, the next deposited layer [2]. Consequently, thixotropy is very important for concrete digital fabrication as it enhances the structuration of cement paste.

From a practical view, thixotropy is mainly affected by CSH nucleation [2]. Thus, a very thixotropic concrete can be created by increasing the rate of nucleation of hydration products in the mixture. One way to increase this rate is by increasing the energy input of mixing [3]. Henceforth, in this work we focus on how mixing could enhance thixotropy. 


\section{Methods and Materials}

\subsection{Materials}

The cement used in this study was CEM I 52.5R, equivalent to ASTM Type I, Ordinary Portland cement of specific gravity 3.15. Its mineralogical composition was obtained through differential thermal and thermogravimetric analysis (DTA-TG). Particle size distribution was measured by laser diffraction using a Malvern Mastersizer 5 instrument (Malvern Instruments Ltd., Malvern, UK). Results are reported in Table 1. In this study, a commercial polycarboxylate ether-type (PCE) high range water reducer was used in liquid form containing $29.5 \%$ of dry polymer.

Table 1. Mineralogical composition and size of the cement powder used in this study.

\begin{tabular}{lllllllll}
\hline Material & $\mathrm{C}_{3} \mathrm{~S}$ & $\mathrm{C}_{2} \mathrm{~S}$ & $\mathrm{C}_{3} \mathrm{~A}$ & $\mathrm{C}_{4} \mathrm{AF}$ & $\mathrm{SiO}_{2}$ & $\mathrm{D}_{\mathrm{v} 10}$ & $\mathrm{D}_{\mathrm{v} 50}$ & $\mathrm{D}_{\mathrm{v} 90}$ \\
\hline Cement & $64 \%$ & $14 \%$ & $2.5 \%$ & $14 \%$ & $21 \%$ & $1.49 \mu \mathrm{m}$ & $8.11 \mu \mathrm{m}$ & $28.75 \mu \mathrm{m}$ \\
\hline
\end{tabular}

\subsection{Mixing Protocol}

A delayed mixing protocol was chosen to reduce the possibility that the aluminates would co-precipitate with the studied admixtures [4]. While complete prevention of coprecipitation is never the case in fresh cement paste, this protocol was repeatable [5]. Cement pastes were prepared using a Turbo test Rayneri VMI mixer with four mixing speeds chosen-840 rpm, $1400 \mathrm{rpm}, 2100 \mathrm{rpm}$, and $2800 \mathrm{rpm}$. The diameters of the mixing blade and beaker were $3 \mathrm{~cm}$ and $8 \mathrm{~cm}$, respectively. The mixing protocol was a three stage process. In the first stage, $200 \mathrm{~g}$ of cement was added to $90 \%$ of the water and then mixed for 90s. In the second stage, the cement paste was left to rest for 20 min, while in the third stage the paste was continuously mixed for 120 s, where at the 60 s mark the remaining water and the PCE was added to the mixing paste. The waterto-cement (w/c) ratio was 0.3 and the PCE dosage was $0.4 \%$ solid content of PCE by weight of cement (bwoc). The amount of water in the PCE solution was considered in the w/c calculation. After the last stage of mixing, the paste was left to rest for another $15 \mathrm{~min}$ in order for the polymer to reach equilibrium in the system. The preparation protocol was the same for the quartz powder system.

For the DLS measurements, the paste was centrifuged at 1000 times the gravitational acceleration $\left(\mathrm{g}=9.81 \mathrm{~m} \cdot \mathrm{s}^{-2}\right)$ for $5 \mathrm{~min}$. The suspending liquid was then extracted and filtered with a polyvinylidene fluoride (PVDF) $0.45 \mu \mathrm{m}$ membrane (Millipore).

\subsection{Rheological Measurements}

Dynamic rheological experiments were conducted using a Bohlin C-VOR shear rheometer equipped with a Vane geometry. The Vane tool diameter, outer cup diameter and depth were $25 \mathrm{~mm}, 50 \mathrm{~mm}$ and $60 \mathrm{~mm}$, respectively. After the mixing process the paste was loaded into the geometry and pre-sheared at $150 \mathrm{~s}^{-1}$ for $150 \mathrm{~s}$ before the start 
of the time sweep dynamic test. In order to measure the evolution of the kinetics of the rigid interactions network, an oscillating strain of amplitude lower than the rigid critical strain [6] was applied. This ensures that the system is purely elastic and the measured stress is in phase with the applied oscillating strain [2]. Thus, the oscillating strain of amplitude was set to $0.03 \%$ at a frequency of $1 \mathrm{~Hz}$. To capture the elastic storage modulus fully the time of the test was set to $2 \mathrm{~h}$.

\subsection{Isothermal Calorimetry}

The thermal power and heat of hydration of the cement pastes were monitored for the first 48 hours using a TAM Air microcalorimeter (Thermometrics) at a constant temperature of $20^{\circ} \mathrm{C}$. Samples were mixed according to the mixing procedure and then $5 \mathrm{~g}$ of paste was placed inside the calorimeter cell. All samples were balanced with a reference cell having the same heat capacity.

\subsection{Dynamic Light Scattering Measurements}

Dynamic Light Scattering (DLS) is generally used to measure the size distribution by intensity of particles in a liquid medium. In this work, the measure scattered intensity was further used to estimate the concentration of particles remaining in the interstitial pore fluid after mixing $[7,8]$. This was done by first recording the scattered intensity. Then the area underneath the intensity curve from $30 \mathrm{~nm}$ to $1000 \mathrm{~nm}$ was computed. This area, referred hereafter as the derived count rate (DCR) of the system, was then used to represent the concentration of nanoparticles in the interstitial pore fluid. Measurements were performed using a Zetasizer nano S from Malvern Instruments, operating at an incident light wavelength of $633 \mathrm{~nm}$, scattered light detection angle of $173^{\circ}$, and constant temperature of $25^{\circ} \mathrm{C}$. Averages of three measurements per specimen were taken.

\section{$3 \quad$ Results}

\subsection{Rheological Measurements}

We plot in Fig. 1 the elastic storage modulus versus time for cement paste mixed at 840 $\mathrm{rpm}$ versus $2800 \mathrm{rpm}$. Our results show that the storage elastic modulus as a function of time increases at a higher rate for the cement paste mixed at $2800 \mathrm{rpm}$ versus 840 rpm. In Fig. 2 we plot the ratio of the elastic storage modulus of the two speeds. We can see it is linear and that the higher speed is approximately four times higher after 2 hours. 


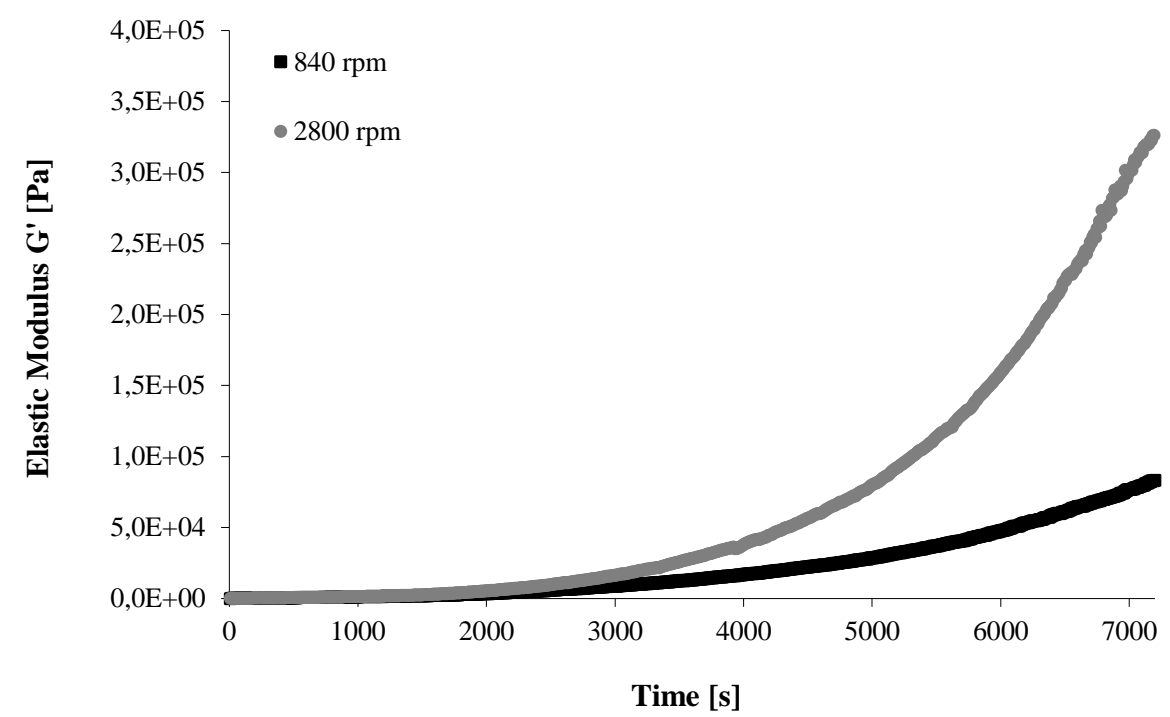

Fig. 1. Effect of mixing intensity on the elastic storage modulus of cement paste samples prepared with w/c ratio of 0.30 and $0.4 \%$ of PCE bwoc.

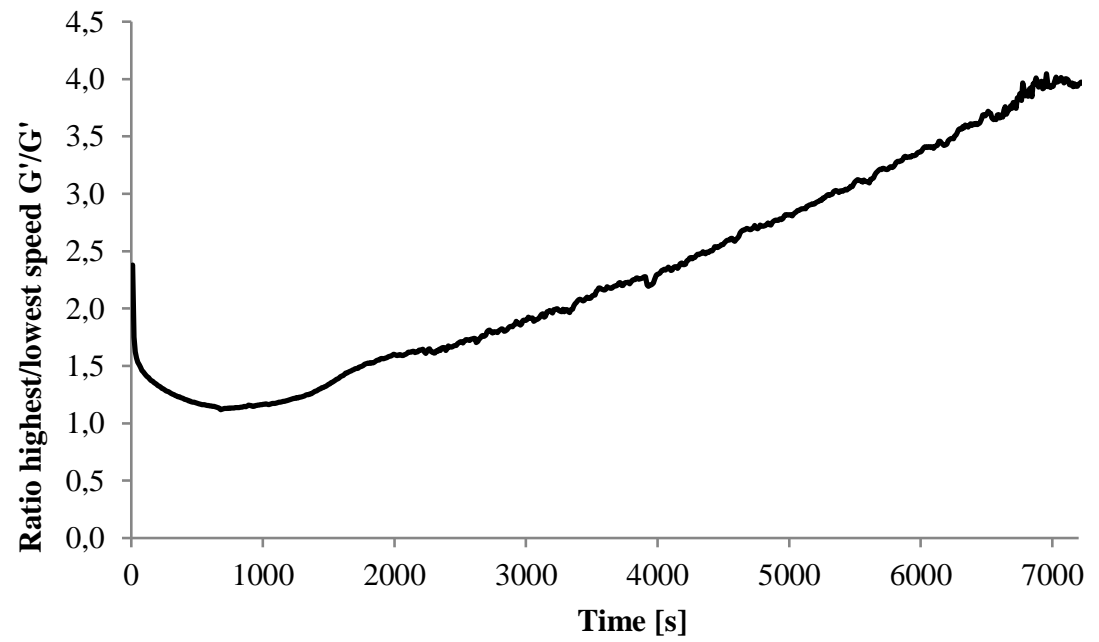

Fig. 2. The ratio between the elastic storage modulus of the $2800 \mathrm{rpm}$ versus $840 \mathrm{rpm}$. 


\subsection{Isothermal Calorimetry}

The heat evolution during the hydration of cement paste mixed at four different mixing speeds is presented in Fig. 4. It is seen that the paste mixed at $2800 \mathrm{rpm}$ reaches its maximum peak almost 4 hours before the paste mixed at $840 \mathrm{rpm}$. The maximum peak of this higher mixed paste reaches almost $1 \mathrm{~mW} \cdot \mathrm{g}^{-1}$ higher in heat flow than the lower mixed paste. In general, our results show that increasing the mixing speed shifts the heat flow curve left, increases the slope and the maximum peak of the heat flow, but does not affect the overall shape of the curve.

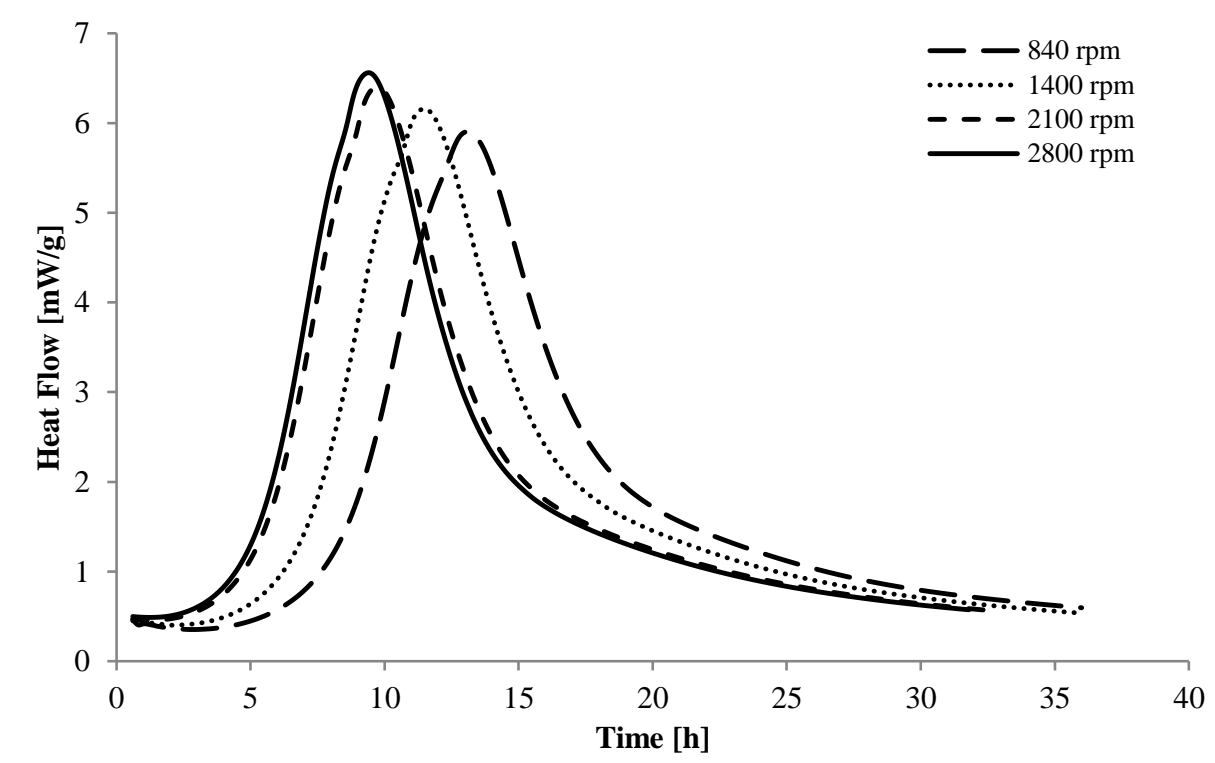

Fig. 4. The heat flow of cement paste (w/c 0.3, PCE dosage $0.4 \%$ ) mixed at different speeds.

We plot in Fig. 5a the rate of the heat flow during the acceleration period and in Fig. $5 \mathrm{~b}$ the time of the maximum peak of heat flow during the acceleration period as a function of mixing speed. There appears to be an almost linear relation for both of these figures with higher mixing showing higher heat flow rates and shorter times to reach the maximum peak. 

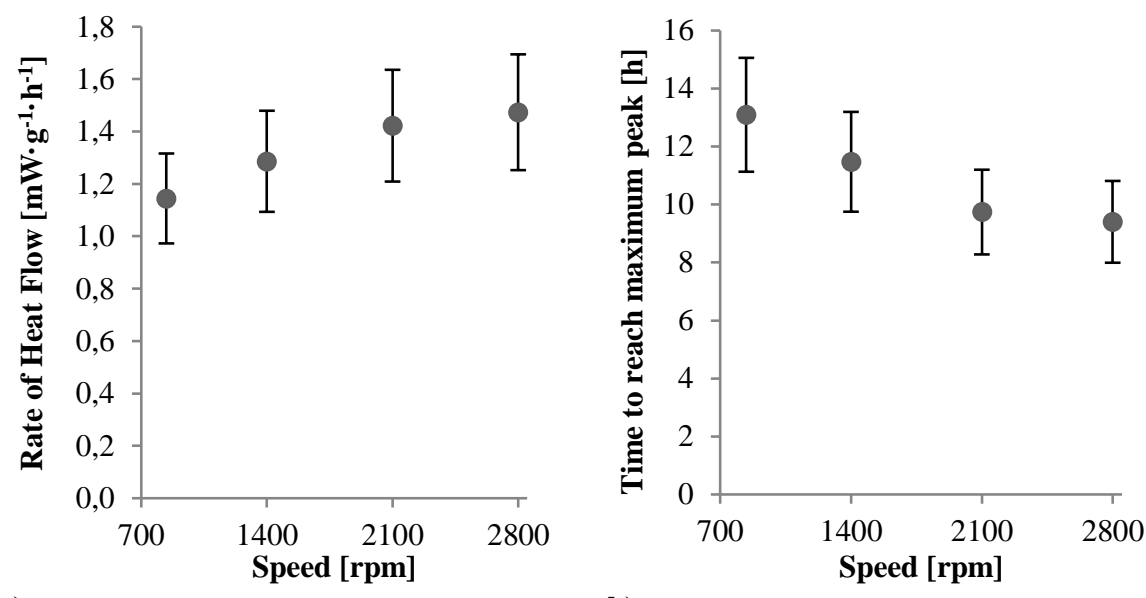

b)

Fig. 5. a) The slope of the heat flow curve during the acceleration period and b) the time to reach the maximum peak as a function of mixing speed.

\subsection{Dynamic Light Scattering Measurements}

We show in Fig. 6 the results of the DLS measurements. We observe that higher mixing enhances the concentration of nanoparticles in a linear fashion. The DCR for the highest speed is half an order higher than the lowest speed.

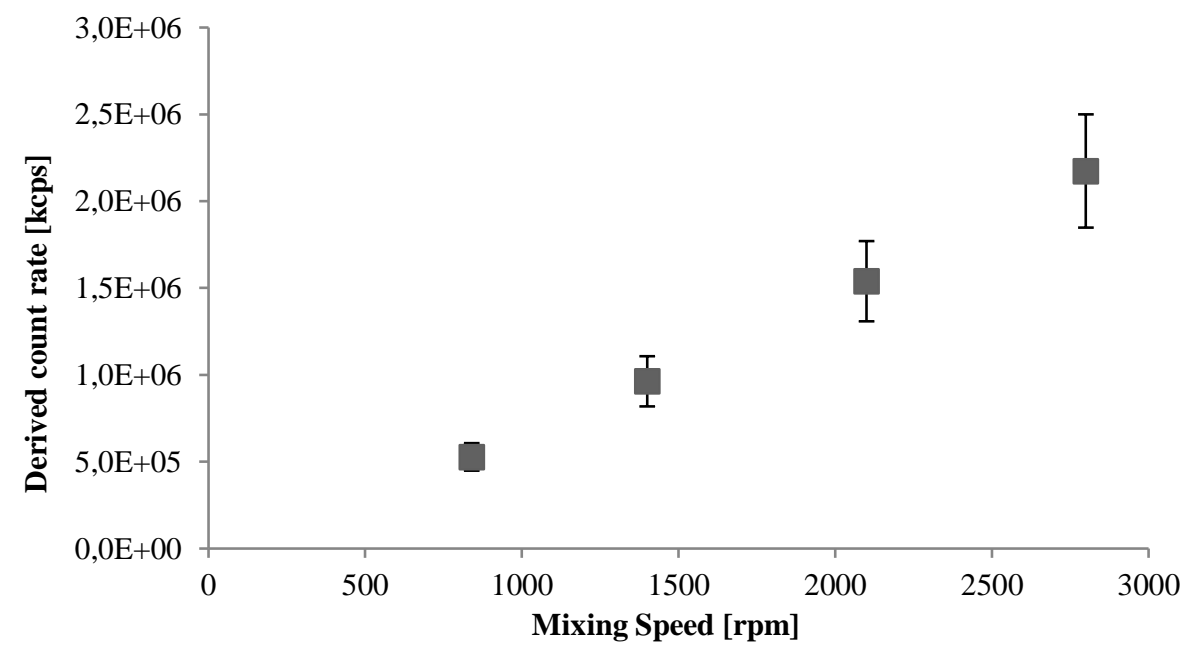

Fig. 6. Cement powder in water (W/C 0.50) with $0.8 \%$ PCE dosage (by weight of cement) and increasing mixing speed. 


\section{Discussion}

The main thing we have shown is that higher mixing enhances the thixotropy, the kinetics of hydration, and the concentration of nanoparticles in the suspending fluid of cement paste. These phenomena have been observed before.

Han and Ferron [9] found that the mixing rate enhanced both the elastic storage modulus and the rate of heat evolution. Juilland et al. [3] were able to demonstrate that two kinetics of cement hydration were affected by the mixing rate - the induction period and the acceleration period. An increase in the mixing rate led to a shortening of the induction period by decreasing the diffuse electrical double layer, which in turn increased the dissolution rate, and hence, the transportation rate of the ions that detached from the cement surface into the bulk pore fluid. The increase in the height of the main heat evolution peak was due to the mechanical action of the mixing, resulting in an increase in the detachment of $\mathrm{C}-\mathrm{S}-\mathrm{H}$ from the surface and their density.

Caruso et al. [8] highlighted the formation of nanoparticles in cement pore solution containing superplasticizers. They asserted that these nano-size particles are either nano-C-S-H, nano-ettringite, nano-AFm, or interamolecular complexes of polymer and cations. However, they could not draw any further conclusions on whether one type of nanoparticle was more present than another and did not consider the consequences of the variations in mixing speed on the generation of these nanoparticles.

Consequently, we suggest that an appropriate combination of mixing energy and super-plasticizer dosage promotes hydration by scratching hydrates from the surface of cement particles, stabilizing them in the suspending fluid and hence generating additional nucleation surfaces.

The physical origins of thixotropy originate mainly from the rigid interactions network of C-S-H nucleation [2]. Thus, with higher mixing power the number of C-S-H bonds created by hydration increases and hence why thixotropy is enhanced and the setting time decreases.

\section{Conclusion}

This study aimed to understand how mixing can enhance the thixotropy of a cement paste. Our results show that the storage elastic modulus as a function of time increases at a higher rate for the cement paste mixed at higher versus lower mixing intensity (i.e. approximately four times higher after 2 hours). Using calorimetry analysis we found that higher mixing decreases the setting time and enhances the peak of the heat flow. By analyzing the nanoparticles present in the suspending fluid of the cement paste we show, in accordance with literature, that an appropriate combination of mixing energy and super-plasticizer dosage promotes hydration by scratching hydrates from the surface of cement particles, stabilizing them in the suspending fluid, and hence, generating additional nucleation surfaces.

These results open the door for low cost cement acceleration through just the mixing as well as the design of printing heads including high-shear micro mixers allowing for a faster liquid-to-solid transition of the printable material. 


\section{References}

1. Lloret E., Shahab A.R., Linus M., Flatt R.J., Gramazio F., Kohler M., Langenberg S.: Complex concrete structures: Merging existing casting techniques with digital fabrication. Computer-Aided Design 60, 40-49 (2015).

2. Roussel N., Ovarlez G., Garrault S., Brumaud C.: The origins of thixotropy of fresh cement pastes. Cem.Concr.Res. 42, 148-157 (2012).

3. Juilland P., Kumar A., Gallucci E., Flatt R.J., Scrivener K.L.: Effect of mixing on the early hydration of alite and OPC systems. Cem.Concr.Res. 42, 1175-1188 (2012).

4. Flatt R. J., Houst Y.F.: A simplified view on chemical effects perturbing the action of superplasticizers. Cem.Concr.Res. 31, 1169-1176 (2001).

5. Hot J., Bessaies-Bey H., Brumaud C., Duc M., Castella C., Roussel N.: Adsorbing polymers and viscosity of cement pastes. Cem.Concr.Res. 63, 12-19 (2014).

6. Nachbaur L., Mutin J.C., Nonat A., Choplin L.: Dynamic mode rheology of cement and tricalcium silicate pastes from mixing to setting. Cem.Concr.Res. 31, 183-192 (2001).

7. Bessaies-Bey H., Baumann R., Schmitz M., Radler M., Roussel N.: Organic admixtures and cement particles: Competitive adsorption and its macroscopic rheological consequences. Cem.Concr.Res. 80, 1-9 (2016).

8. Caruso F., Mantellato S., Palacios M., Flatt R.J.: ICP-OES method for the characterization of cement pore solutions and their modification by polycarboxylate-based superplasticizers. Cem.Concr.Res. 91, 52-60 (2017).

9. Han D., Ferron R.D.: Effect of mixing method on microstructure and rheology of cement paste. Constr.Build.Mater. 93, 278-288 (2015). 